\title{
Microstructure of Oxide Insulator Coating before and after Thermal Cycling Test*
}

\author{
Yoshimitsu HISHINUMA, Satoshi MURAKAMI ${ }^{1)}$, Kenji MATSUDA ${ }^{1)}$, Tsutomu TANAKA ${ }^{2)}$, \\ Yuzo TASAKI ${ }^{2)}$, Teruya TANAKA, Takuya NAGASAKA, Akio SAGARA and Takeo MUROGA \\ National Institute for Fusion Science, Toki, Gifu 509-5292, Japan \\ ${ }^{1)}$ University of Toyama, Toyama 930-0877, Japan \\ ${ }^{2)}$ Toshima MFG. Co.,Ltd, Higashi-matsuyama, Saitama, Japan
}

(Received 9 December 2011 / Accepted 19 April 2012)

Erbium oxide $\left(\mathrm{Er}_{2} \mathrm{O}_{3}\right)$ was shown to be a high potential candidate for tritium permeation barrier and electrical insulator coating for advanced breeding blanket systems such as liquid $\mathrm{Li}, \mathrm{Li}-\mathrm{Pb}$ or molten-salt blankets. Recently, we succeeded to form $\mathrm{Er}_{2} \mathrm{O}_{3}$ coating layer on large interior surface area of metal pipe using Metal Organic Chemical Vapor Deposition (MOCVD) process. In this paper, we investigated the microstructure of $\mathrm{Er}_{2} \mathrm{O}_{3}$ coating layer on stainless steel 316 (SUS 316) plate before and after heat treatments with hydrogen or argon gases. From the results of TEM observations, we confirmed that $\mathrm{Er}_{2} \mathrm{O}_{3}$ coating layer with $700 \mathrm{~nm}$ thickness was formed on the SUS 316 plate and this layer was identified to poly-crystal phase because the diffraction fleck which was arranged like a ring was observed in the selected electron diffraction pattern. No macroscopic defects such as crack and peeling in $\mathrm{Er}_{2} \mathrm{O}_{3}$ coating layer were observed before and after thermal cycling test. The change of microstructure of the $\mathrm{Er}_{2} \mathrm{O}_{3}$ coating layer on before and after heat cycling test was reported.

(c) 2012 The Japan Society of Plasma Science and Nuclear Fusion Research

Keywords: blanket system, $\mathrm{Er}_{2} \mathrm{O}_{3}$, MOCVD coating, heat cycling, TEM observation

DOI: $10.1585 /$ pfr.7.2405127

\section{Introduction}

In the magnetic confinement fusion reactor, it was well known that the Magneto Hydrodynamic (MHD) pressure drop was required in the liquid metal lithium breeding blanket system [1]. An electrically insulating coating with oxide ceramics is one of the attractive methods to break off electromagnetic force for the MHD pressure drop. On the other hand, a ceramic coating would also be necessary to suppress the tritium permeation in a molten salt type blanket systems using Flibe or Flinak as the breeding and cooling fluid [2]. Anyway, MHD pressure drop and tritium leakage are key issues to realize an advanced breeding blanket systems. Also, the both selection of coating material and coating process were necessary to comply with the advanced breeding blanket system. Some ceramic materials such as $\mathrm{CaO}, \mathrm{Y}_{2} \mathrm{O}_{3}, \mathrm{CaZrO}_{3}, \mathrm{AlN}$ and $\mathrm{Er}_{2} \mathrm{O}_{3}$ have been studied historically as the candidate materials for the insulating coating $[3,4]$. Based on these studies, $\mathrm{Er}_{2} \mathrm{O}_{3}$ was selected as one of the candidate materials for the insulator coating for reducing the MHD pressure drop because of high compatibility with liquid $\mathrm{Li}$ and high electrical resistivity [4]. In the previous studies, the various small insulator coatings to investigate the coating characteristics were developed by Physical Vapor Deposition (PVD) methods via RF-sputtering and arc source plasma
[5]. However, the PVD methods have limited capability in coating on complex surfaces expected in the blanket components. It is important to develop new forming methods of large area $\mathrm{Er}_{2} \mathrm{O}_{3}$ coating on the inner and outer surface of the complex shaped duct tubing for the advanced liquid metal breeder blanket application.

Recently, we succeeded the Metal organic chemical vapor deposition (MOCVD) process as a new technology for large area coating on broad and complicated shaped components. MOCVD process is a concise procedure to form homogeneous and large area coating layer synthesized with a vapor transition from a metal organic complex [6-8]. It has the possibility to form homogeneous and large area coating layer into the interior surface of the metal tube using vapor flowing control.

However, the characteristics of $\mathrm{Er}_{2} \mathrm{O}_{3}$ coating film via MOCVD process were not sufficiently understood. We scoped the change of the microstructure of $\mathrm{Er}_{2} \mathrm{O}_{3}$ coating film before and after thermal cycling up to blanket operation temperature. In this paper, the microstructure of $\mathrm{Er}_{2} \mathrm{O}_{3}$ coating film after several times of thermal cycling was studied using X-ray diffraction (XRD), Scanning Electron Microscope (SEM) and Transmission Electron Microscope (TEM) analyses.

author's e-mail: hishinuma.yoshimitsu@nifs.ac.jp

*) This article is based on the presentation at the 21st International Toki Conference (ITC21). 


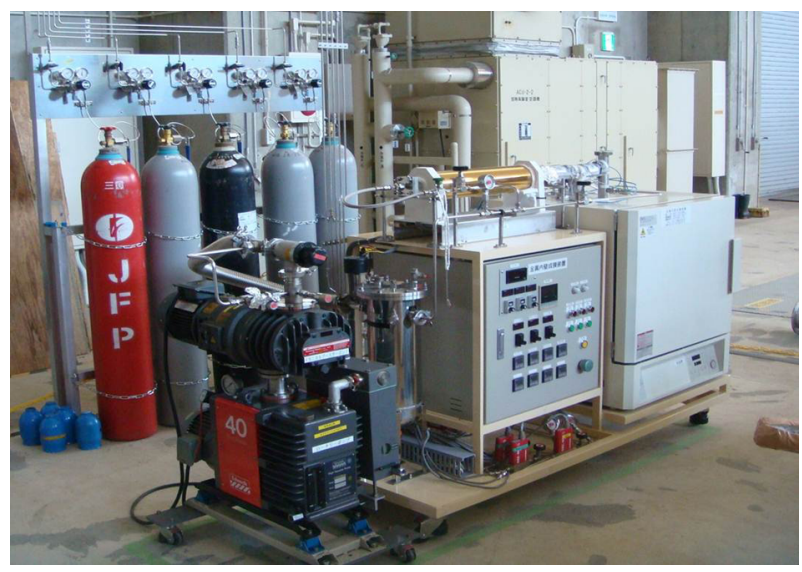

Fig. 1 Large area MOCVD apparatus in NIFS.

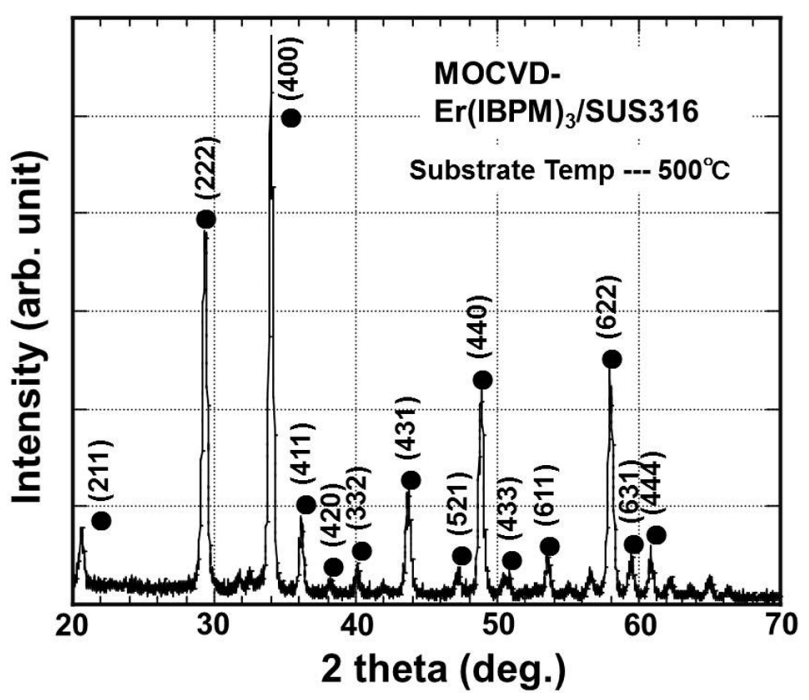

Fig. 2 Typical XRD pattern of surface area in MOCVD coating sample.

\section{Sample Preparation}

All of $\mathrm{Er}_{2} \mathrm{O}_{3}$ coating films were formed on stainless steel 316 (SUS 316) disk plate using MOCVD apparatus in NIFS shown in Fig. 1. The principle and configuration of MOCVD processing was already described in detail in Refs. [6-8]. The dimension of SUS 316 disk is $17 \mathrm{~mm}$ in diameter and $1 \mathrm{~mm}$ in thickness. The coating deposition temperature and time were fixed to $500^{\circ} \mathrm{C}$ and 2 hours. Typical XRD pattern of the surface area in coating layer via MOCVD process is shown in Fig. 2. According to the crystal database such as ICDD, $\mathrm{Er}_{2} \mathrm{O}_{3}$ is cubic crystal and its theoretical lattice parameter is $10.546 \AA$. All of main peaks in XRD were identified as $\mathrm{a}_{2} \mathrm{O}_{3}$ phase. $\mathrm{Er}_{2} \mathrm{O}_{3}$ crystals were oriented randomly in coating layer, and it was clear that $\mathrm{Er}_{2} \mathrm{O}_{3}$ phase via MOCVD process did not have alignment texture. Average lattice parameter estimated by Mirror Index of XRD was also obtained to $10.547 \AA$. These suggested that the single $\mathrm{Er}_{2} \mathrm{O}_{3}$ phase was formed uniformly on the SUS 316 metal substrate via MOCVD process. A part of the coating sample was cut

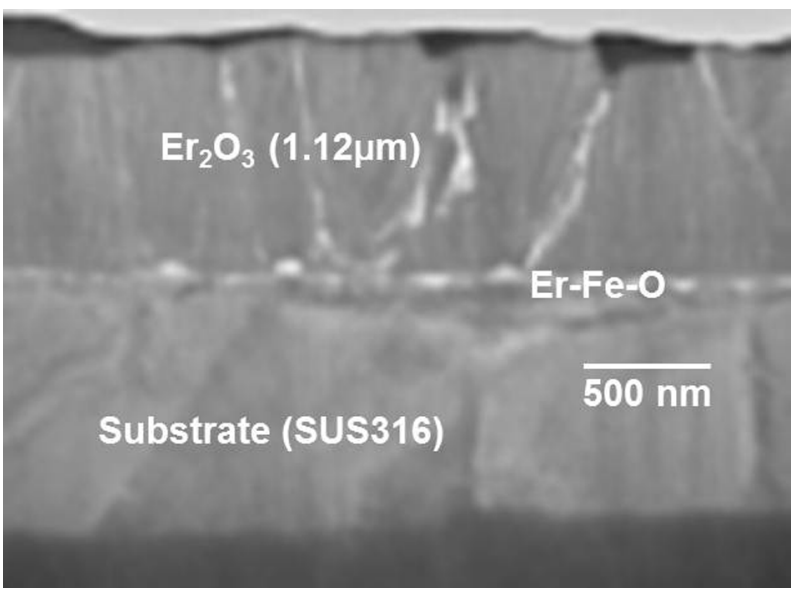

Fig. 3 TEM image of cross-sectional area in $\mathrm{Er}_{2} \mathrm{O}_{3}$ coating layer via MOCVD process.

using FIB apparatus, and microstructure observation using SEM and TEM was carried out. Figure 3 shows TEM image of the cross-sectional area in $\mathrm{Er}_{2} \mathrm{O}_{3}$ coating layer via MOCVD process. The thickness of $\mathrm{Er}_{2} \mathrm{O}_{3}$ coating layer was obtained to be about $700 \mathrm{~nm}$. $\mathrm{Er}_{2} \mathrm{O}_{3}$ coating layer was grown densely like columnar grain texture. We also confirmed Er-Fe-O layer formation at the interface $\mathrm{Er}_{2} \mathrm{O}_{3}$ layer and SUS 316 substrate. This was caused by the Fe diffusion from SUS 316 substrate into coating layer during MOCVD processing. In the boundary of $\mathrm{Er}_{2} \mathrm{O}_{3}$ and SUS 316 substrate, there was no macro defect such as crack and adhesion was also observed.

\section{Heat Treatment under High Pres- sure Hydrogen Gas Atmosphere}

At first, we carried out the heat treatment test under high pressure hydrogen gas using hydrogen permeation test facility in NIFS $[9,10]$. The $\operatorname{Er}_{2} \mathrm{O}_{3}$ coating layer was set to the high pressure hydrogen side and it was heated up to $700^{\circ} \mathrm{C}$ with hydrogen exposure.

Figure 4 shows that typical SEM images of surface of $\mathrm{Er}_{2} \mathrm{O}_{3}$ coating layer before and after heat treatment under hydrogen atmosphere. In the sample surface before heat treatment, small granular-like grains were observed uniformly, and granular size of $\mathrm{Er}_{2} \mathrm{O}_{3}$ coating was obtained to about $1.0 \mu \mathrm{m}$. In the case of the sample after heat treatment, granular-like grains were also observed. No appreciable change of surface microstructure before and after heat treatment under hydrogen atmosphere was confirmed. Typical selected area diffraction (SAD) images of the $\mathrm{Er}_{2} \mathrm{O}_{3}$ coating layer before and after heat treatment under hydrogen atmosphere is shown in Fig. 5. In the SAD patterns of the samples before and after heat treatment, it was clear that the all diffraction flecks which show the crystallization was arranged like a ring shaped. And they were identified to the all Mirror Indexes of $\mathrm{Er}_{2} \mathrm{O}_{3}$ crystal. It suggested that $\mathrm{Er}_{2} \mathrm{O}_{3}$ coating layer was stable under hydrogen atmosphere It mentioned that $\mathrm{Er}_{2} \mathrm{O}_{3}$ coating layer 


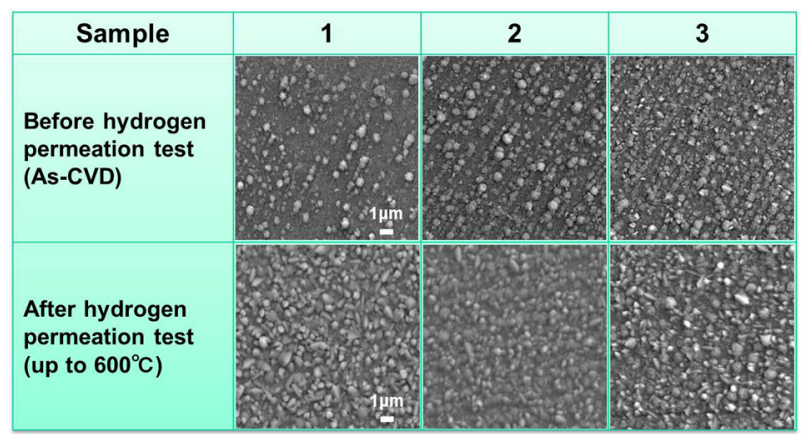

Fig. 4 Typical SEM images of surface area in $\mathrm{Er}_{2} \mathrm{O}_{3}$ coating layer before and after heat treatment under hydrogen atmosphere.
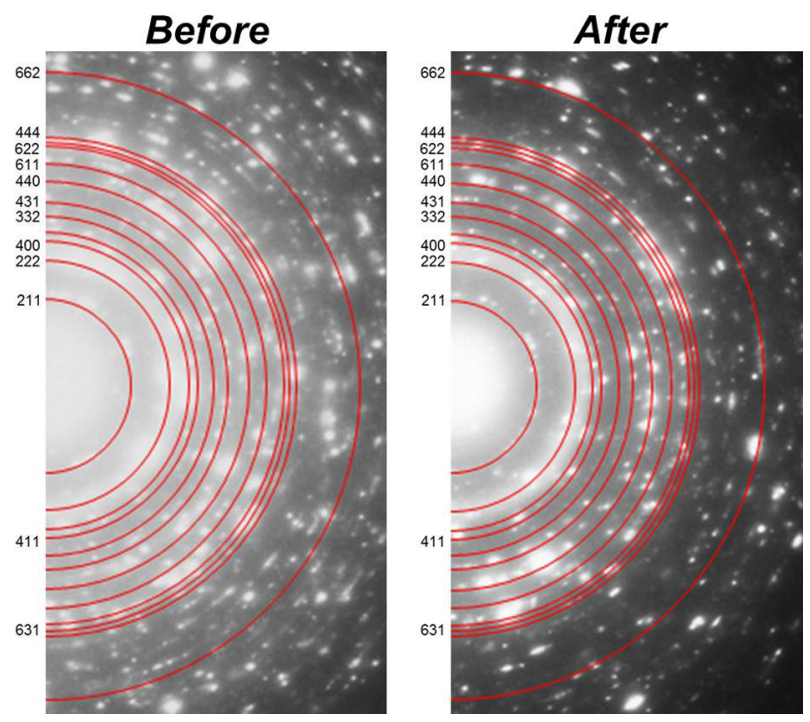

Fig. 5 Typical selected area diffraction (SAD) image of the $\mathrm{Er}_{2} \mathrm{O}_{3}$ coating layer before and after thermal cycling under hydrogen atmosphere.

has high soundness against high temperature under hydrogen atmospheres

\section{Thermal Cycling Test under Ar Gas Atmosphere}

In order to evaluate the change of microstructure, the thermal cycling tests were carried out. The number of thermal cycling in Ar atmosphere was 10 and 30 times. Figure 6 shows that typical temperature profile on 10 times of the thermal cycling for example. The temperature setting of thermal cycling was $700^{\circ} \mathrm{C}$. The temperature was elevated rapidly at a rate of $700^{\circ} \mathrm{C} /$ hour and then it was kept stably during 1 hour. After that, temperature was lowered to $50^{\circ} \mathrm{C}$ by furnace cooling. This temperature profile was repeated to 10 and 30 times on the thermal cycling tests. Figure 7 shows that the comparisons of XRD pattern in $\mathrm{Er}_{2} \mathrm{O}_{3}$ coating layer before and after thermal cycling tests. The peak intensity of (400) plane of $\mathrm{Er}_{2} \mathrm{O}_{3}$ phase was

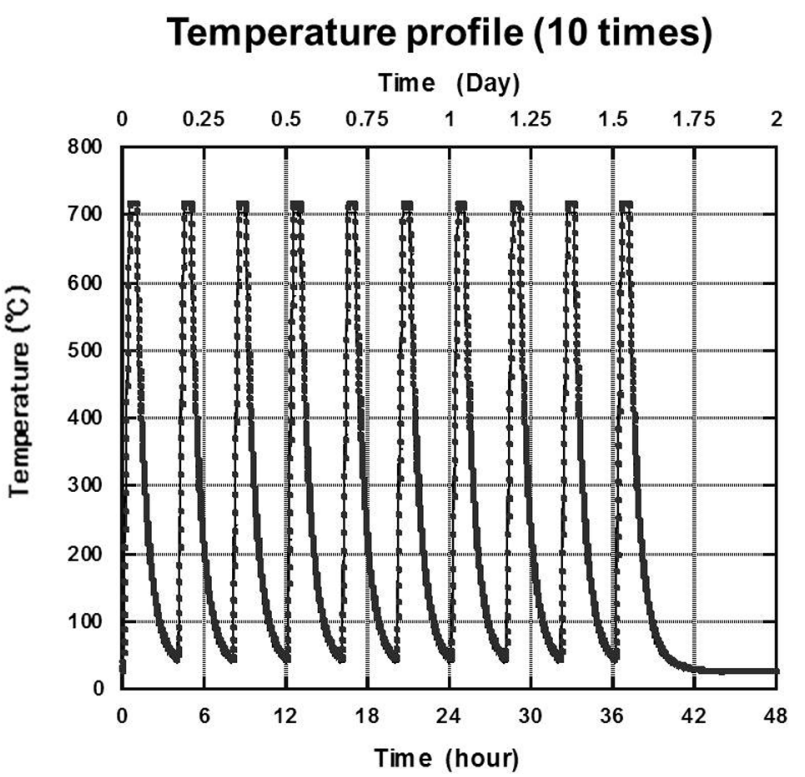

Fig. 6 Typical temperature profile of 10 times thermal cycling under Ar atmosphere.

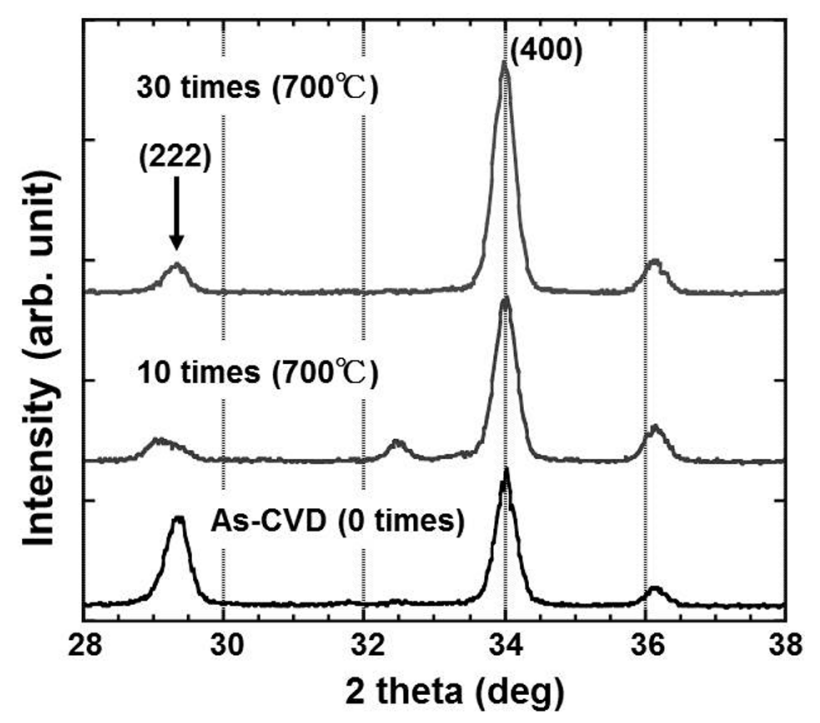

Fig. 7 The comparisons of XRD pattern in $\mathrm{Er}_{2} \mathrm{O}_{3}$ coating layer before and after thermal cycling under Ar atmosphere ( 0 , 10 and 30 times).

increased with increasing number of thermal cycling. Furthermore, the peak intensity ratio such as $(400) /(222)$ was also increased from 1.52 to 7.20 with 30 times thermal cycling. These suggested that a-axis alignment of $\mathrm{Er}_{2} \mathrm{O}_{3}$ texture was promoted by the increase of number of thermal cycling. It mentioned that $\mathrm{Er}_{2} \mathrm{O}_{3}$ grain growth was promoted to a-axis direction by the annealing effect due to the thermal cycling.

\section{Conclusions}

We investigated about the change of microstructure of $\mathrm{Er}_{2} \mathrm{O}_{3}$ coating layer via MOCVD process before and after 
the thermal cycling. As MOCVD process, $\mathrm{Er}_{2} \mathrm{O}_{3}$ coating layer on SUS 316 substrate was formed alike granular and non-alignment texture. In the heat treatment under hydrogen atmosphere, $\mathrm{Er}_{2} \mathrm{O}_{3}$ coating layer was stable without reduction. We confirmed that $\mathrm{Er}_{2} \mathrm{O}_{3}$ coating layer has high soundness against high temperature and hydrogen atmosphere. We also confirmed that a-axis alignment of $\mathrm{Er}_{2} \mathrm{O}_{3}$ texture was prompted by the thermal cycling under argon atmosphere. It suggested that $\mathrm{Er}_{2} \mathrm{O}_{3}$ grain growth was promoted to a-axis direction by the annealing effect due to the thermal cycling.

\section{Acknowledgements}

This work was mainly supported by the Fusion Engineering Research (FER) Project (UFFF026) in NIFS and, in part by the Grant-in-Aid for Scientific Research (A) 21246141 (2009-2012) from MEXT.

[1] S. Malang, H.U. Borgstedt, E.H. Farnum, K. Natesan and I.V. Vitkovski, Fusion Eng. Des. 27, 570 (1995).
[2] T. Muroga, T. Tanaka and A. Sagara, Fusion Eng. Des. 81, 1203 (2006).

[3] D.L. Smith, J. Konys, T. Muroga and V. Evtikhin, J. Nucl. Mater. 307-311, 1314 (2002).

[4] B.A. Pint, P.F. Tortorelli, A. Jankowski, J. Hayes, T. Muroga, A. Suzuki, O.I. Yeliseyeva and V.M. Chernov, J. Nucl. Mater. 329-333, 119 (2004).

[5] A. Sawada, A. Suzuki, H. Maier, F. Koch, T. Terai and T. Muroga, Fusion Eng. Des. 75-79, 737 (2005).

[6] Y. Hishinuma, T. Tanaka, T. Tanaka, T. Nagasaka, S. Yoshizawa, Y. Tasaki and T. Muroga, J. Nucl. Mater. 417, 1214 (2011).

[7] Y. Hishinuma, T. Tanaka, T. Tanaka, T. Nagasaka, Y. Tasaki, A. Sagara and T. Muroga, Fusion Eng. Des. 86, 2530 (2011).

[8] Y. Hishinuma, T. Tanaka, T. Tanaka, T. Nagasaka, Y. Tasaki, S. Murakami, K. Matsuda, A. Sagara and T. Muroga, Fusion Sci. Technol. 60, 1131 (2011).

[9] D. Zhang, T. Tanaka and T. Muroga, J. Nucl. Mater. 417, 1249 (2011).

[10] T. Tanaka, T. Muroga, D. Zhang and T. Nagai, Annual Report of National Institute for Fusion Science, Apr.2009Mar.2010, 451 (2010). 